\title{
Psychopathic Traits in Adolescents and Recognition of Emotion in Facial Expressions
}

\author{
Traços Psicopáticos em Adolescentes e Reconhecimento \\ de Emoções Expressas pela Face
}

\author{
Silvio José Lemos Vasconcellos ${ }^{a}$, Roberta Salvador-Silva*, ${ }^{*}$, Viviane Gauer $^{b}$ \\ \& Gabriel José Chittó Gauer ${ }^{b}$ \\ ${ }^{a}$ Universidade Federal de Santa Maria, Santa Maria, RS, Brasil \\ $\&{ }^{b}$ Pontifícia Universidade Católica do Rio Grande do Sul, Porto Alegre, RS, Brasil
}

\begin{abstract}
Recent studies have investigated the ability of adult psychopaths and children with psychopathy traits to identify specific facial expressions of emotion. Conclusive results have not yet been found regarding whether psychopathic traits are associated with a specific deficit in the ability of identifying negative emotions such as fear and sadness. This study compared 20 adolescents with psychopathic traits and 21 adolescents without these traits in terms of their ability to recognize facial expressions of emotion using facial stimuli presented during 200 milliseconds, 500 milliseconds, and 1 second expositions. Analyses indicated significant differences between the two groups' performances only for fear and when displayed for $200 \mathrm{~ms}$. This finding is consistent with findings from other studies in the field and suggests that controlling the duration of exposure to affective stimuli in future studies may help to clarify the mechanisms underlying the facial affect recognition deficits of individuals with psychopathic traits.

Keywords: Psychopathic traits, facial expression, emotion, social cognition, psychopathy.
\end{abstract}

\begin{abstract}
Resumo
Estudos recentes têm investigado a capacidade de psicopatas adultos e crianças com traços de psicopatia identificarem determinadas emoções expressas pela face. Resultados conclusivos quanto ao fato dos traços de psicopatia mostrarem-se associados a deficiências na capacidade de identificar emoções negativas, a exemplo de medo e tristeza, ainda não foram alcançados. O presente estudo comparou 20 adolescentes com traços de psicopatia e 21 adolescentes sem traços de psicopatia no que se refere à capacidade de reconhecer emoções expressas pela face em tempos de exposição de 200 milissegundos, 500 milissegundos e 1 segundo. As análises indicaram diferenças estatísticas significativas entre os dois grupos somente para o reconhecimento de medo em um tempo de exposição de 200 milissegundos. Esses achados são consistentes com outros estudos nesse campo e sugerem que o controle do tempo de exposição dos estímulos afetivos em pesquisas futuras pode ajudar a elucidar mecanismos subjacentes relacionados à deficiência, na esfera afetiva, de reconhecimento das expressões faciais em indivíduos com traços de psicopatia.

Palavras-chave: Traços de psicopatia, expressões faciais, emoções básicas, cognição social; psicopatia.
\end{abstract}

Psychopathy is a severe personality disorder in which individuals present an altered capacity to inhibit and regulate socially inappropriate behavior as well as an inability to understand and experience certain emotions (Cleckley, 1976; Hare, 1993). Individuals afflicted with this disorder tend to be little affected by other people's emotions and, thus, are inclined to act against the people with whom they interact.
Although the modern conception of psychopathy derives from a series of clinical observations made by Hervey Cleckley, attempts at understanding the emotional distancing and antisocial behaviors associated with the disorder have a longer history. In the nineteenth century, scholars such as Philip Pinel and Benjamin Rush described disorders with symptoms similar to those of what is now called psychopathy. Their works try to explain the lack of empathy in some individuals that did not derive from manic or delirious states.

Currently, many authors speculate that psychopathy is directly linked with a deficit in processing information about various types of emotional content. These 
Vasconcellos, S. J. L., Salvador-Silva, R., Gauer, V. \& Gauer, G. J. C. (2014). Psychopathic Traits in Adolescents and Recognition of Emotion in Facial Expressions.

characteristics do not, as some authors stress, suddenly develop when an individual reaches adulthood (Blair, 2008), traits and tendencies that can culminate in a psychopathic disorder are identifiable at earlier ages (Forth, Kosson, \& Hare, 2003).

Conceptions such as these can explain the alluded "coldness" in psychopathic individuals. At the root of many antisocial behaviors, therefore, would be a lesser capacity for responding adequately to other individuals' emotions. Studying the ability of psychopaths to identify basic facial expressions of emotion has been a way of investigating the deficits related to their weaker emotional responsiveness. Works on this theme may lead to a greater understanding of these specific deficiencies, given the different types of universal emotions that can be expressed by facial muscles. However, it can also be said that, so far, research in this area has not yielded conclusive data on the true deficiencies characterizing psychopaths or individuals with traits of psychopathy in terms of understanding other people's emotions, suggesting the need for more specifics in this field (Glass \& Newman, 2006).

Two specific studies with adults (Blair et al., 2004; Blair et al., 2002), for example, demonstrated a lesser capacity in psychopaths to identify different affective expressions of fear and sadness. Stevens, Charman, and Blair (2001), utilizing the Psychopathy Screening Device (PSD), revealed specific deficits in children with psychopathic tendencies in terms of processing fear and sadness. However, Kosson, Suchy, Mayer, and Libby (2002), did not find these deficits in their work, which showed in adults a deficiency in processing revulsion. Dolan and Fullam (2006) observed a negative correlation between psychopathy scores measured by the Psychopathy Check-List - Screen Version (PCL-SV) and recognizing sadness.

Hansen, Johnsen, Hart, Waage, and Thayer (2008), examining the various facets that compose psychopathy, established a connection between the third and fourth facets with the ability to identify revulsion. They did not, however, find any connection between the investigated facets with the ability to identify fear and sadness. Del Gaizo and Flakenback (2007) took into consideration in their work the distinction between primary and secondary psychopathy. Their findings indicated that primary psychopathy has a positive correlation with accurately perceiving fear. Secondary psychopathy, however, showed no connection to recognizing emotions.

Hastings, Tangney, and Stuewig (2008), drawing on stimuli presenting different intensity levels of emotion in facial expressions, obtained data suggesting that psychopaths have a greater deficit in recognizing information with affective content. The authors, however, did not acquire more significant and specific evidence in terms of identifying fear. Glass and Newman (2006), using different task versions for recognizing facial expressions with and without previous clues, did not find specific deficiencies in psychopaths in terms of processing emotional information. According to these authors, the conditions for demonstrating affective deficits in psychopaths still require more investigations. Pham and Philippot (2010) also utilized facial expressions with different intensity levels. Their data suggested differences due to education levels but not, however, a connection to the presence or absence of the disorder.

Marsh and Blair (2008) examined 20 publications on the antisocial population in a meta-analysis study. Their results implied a connection between antisocial behavior and recognizing fear. Their meta-analysis indicated, furthermore, that in this field, investigating deficits in recognizing facial expressions tied to basic emotions relies on diverse methods. Studies with samples of antisocial individuals, including psychopaths, have employed differentiated presentation times for the stimuli (Marsh \& Blair, 2008). It should be noted that most researches evaluating the recognition of facial expressions by psychopaths used periods equal to or greater than one second, including studies without any time limits for presenting the stimuli.

Over the last decade, a series of studies investigated the connection between psychopathy and the ability to identify facial expressions. Methodologies that do not completely overlap seek not only to explore constitutive and different aspects of psychopathy but also variations in the task of identifying emotions. Although most studies in this field focus on adults, some worked with children and evaluated psychopathic tendencies. The present article will now describe a study aiming to compare adolescents with and without traits of psychopathy in terms of their ability to recognize facial expressions of emotion, using different time periods for the stimuli. The durations used are more like the real situations of social interaction. This work received support from the Rio Grande do Sul Research Support Foundation (Fundação de Amparo à Pesquisa do Rio Grande do Sul [FAPERGS]).

\section{Method}

\section{Participants}

Based on an initial interview by a psychologist at a correctional institution, 30 male adolescents whose records indicated severe and frequent antisocial behaviors and 30 others with less severe and frequent antisocial behaviors were invited to participate in the study. All youth were between the ages of 13 and 19. This first stage also made it possible to select only adolescents who were able to read and who were without clinical signs of mental retardation or psychotic symptoms. These 60 adolescents were assessed for psychopathic traits, leading to a final sample of 20 adolescents with PCL: YV scores of 30 and above (mean age $=16.3 ; S D=1.6$ ) and 21 adolescents with PCL: YV scores of 20 or lower (mean age $=16.7 ; S D=$ 1.3). The youth with and without psychopathic traits were comparable in educational history, averaging 4.6 $(S D=$ $1.3)$ and 4.8 years of study $(S D=1.6)$. 


\section{Measures}

The Hare Psychopathy Checklist: Youth Version (PCL:YV) is a 20-item scale for evaluating psychopathic traits in adolescents, adapted from the Hare Psychopathy Checklist - Revised (PCL - R; Hare, 2003). Each item is scored 0,1 , or 2 to indicate the absence, partial presence, or complete presence of each trait or disposition. A version of the PCL:YV has been translated into the Portuguese language and adapted for use in Brazil, and preliminary results indicate its reliability $(W=.93 ; p<.001$; Ronchetti, Davoglio, Salvador-Silva, Vasconcellos, \& Gauer, 2010).

As with the scale for adults, the PCL:YV assesses the interpersonal, affective, and behavioral characteristics related to psychopathy. The instrument is scored on the basis of semi-structured interviews lasting 60 to 90 minutes and a cross-check of the interview information, using data about the personal history of each participant obtained from other sources. In this study, collateral information was obtained from an interview with a correctional officer at the institution where the adolescents were incarcerated.

\section{Facial Expression Recognition Brazilian Task (FERBT)}

In order to evaluate the ability to recognize facial expressions of emotion, a computer program was designed to control stimulus exposure time on the computer screen. First, 80 photographs of four professional actors (two men and two women) were produced to represent the multiraciality characterizing the Brazilian population (White, Mixed-race, and Black). Photos were selected to express fear, sadness, happiness, disgust, surprise, and anger based on evidence for the universality of these emotions (Ekman, 1992, 2003). A theater director supervised the production of photos, guiding the actors as needed to make the expressions more representative.

Facial stimuli were selected on the basis of a pilot study. The first part of the pilot study was conducted to select the photos to be used in subsequent studies. The 80 pictures were printed on paper sheets and viewed by 110 college students. In this phase, students were instructed to identify the expressed emotion without time limits. Twenty four pictures were chosen that yielded correct classifications for $75 \%$ to $95 \%$ of the sample. The second part of the pilot study presented each of these 24 pictures to another set of 100 students in three separate blocks of trials for durations of $200 \mathrm{~ms}, 500 \mathrm{~ms}$ and $1 \mathrm{~s}$. After viewing each picture, participants indicated on a piece of paper which of the six basic emotions had been presented. The order of presentation was random but consistent across blocks. At all three exposure times, the mean correct identification rate was at least $50 \%$, demonstrating that, even given brief stimulus presentations, the basic emotions could be identified by most nonclinical participants.

\section{Procedures}

Interviews occurred in two isolated rooms in the institution. These two rooms provided good lighting and adequate soundproofing. The psychopathy assessment interviews were conducted by a psychologist and a psychiatrist who had received training in applying the PCL:YV from D. S. Kosson. They were in charge of validating this instrument in Brazil. After the interviews, participants completed the facial affect recognition task. Two notebook computers with 15-inch screens were used to present the images approximately 50 centimeters away from each participant. All participants were provided with a list of six basic emotions and were asked to verbally indicate the emotion presented in each photo. There was no stipulated minimum time frame for answering after each image was presented. After researchers wrote down each answer, participants confirmed they were ready for the next trial before the subsequent image was presented. The task of identifying emotional facial expressions lasted an average of 20 minutes.

\section{Results}

The affect recognition performance data for the two groups for the six basic emotions at each image presentation time are presented in Table 1.

A Student $t$-test compared the two groups in their ability to identify fear, sadness, anger, disgust, and surprise at each of the three stimulus duration times. Because the performance data for happiness were neither symmetric nor mesokurtic, a nonparametric Mann-Whitney test was used to compare the groups in happiness recognition for the three different stimulus durations. Happiness is commonly the most easily identifiable emotion in studies with non-clinical samples (Ekman, 2003).

The group high in psychopathic traits was significantly poorer than the group low in psychopathic traits only in identifying fear in faces presented for $200 \mathrm{~ms}, t(39)=$ $-2.08, p=.04, d=.66$. No significant statistical differences were found in the other experimental conditions, including the identification of fear in faces presented for 500 milliseconds and 1 second. However, the moderate effect size for fear faces at $500 \mathrm{~ms}, t(39)=-1.51, p=.14$, $d=.48$, suggests a non-trivial performance difference for fear at this duration. No other group differences approached significance, although small-to-moderate effect sizes suggesting non-significant superiority for the group high in psychopathic traits were identified for several other conditions (See Table 1).

\section{Discussion}

The present study investigated the connection between traits of psychopathy that manifest during adolescence and the ability to identify facial expressions of emotion. Towards this end, a new measure of affect recognition was constructed and validated in Brazil. This instrument took into consideration the Brazilian population's ethnic diversity so as to minimize any dissonance deriving from employing tests standardized for use in other countries. Furthermore, this instrument afforded control over 
Vasconcellos, S. J. L., Salvador-Silva, R., Gauer, V. \& Gauer, G. J. C. (2014). Psychopathic Traits in Adolescents and Recognition of Emotion in Facial Expressions.

Table 1

Recognition of Facial Affect Accuracy for Youth High in Psychopathic Traits and for Youth Low in Psychopathic Traits

\begin{tabular}{|c|c|c|c|c|c|c|c|c|c|}
\hline & \multicolumn{3}{|c|}{$\begin{array}{l}\text { High PCL:YV Group } \\
\qquad(n=20)\end{array}$} & \multicolumn{3}{|c|}{$\begin{array}{l}\text { Low PCL:YV Group } \\
\qquad(n=21)\end{array}$} & \multicolumn{2}{|c|}{ Significance } & \multirow[t]{2}{*}{ Effect Size } \\
\hline & $\begin{array}{c}\text { Accuracy } \\
(\%)\end{array}$ & Mean & $S D$ & $\begin{array}{c}\text { Accuracy } \\
(\%)\end{array}$ & Mean & $S D$ & $t$ & $p$ & \\
\hline Anger $200 \mathrm{~ms}$ & 65 & 2.60 & 1.10 & 56 & 2.24 & 1.38 & .93 & .36 & .29 \\
\hline Anger $500 \mathrm{~ms}$ & 68.75 & 2.75 & 1.21 & 60.75 & 2.43 & 1.03 & .92 & .36 & .28 \\
\hline Anger $1 \mathrm{~s}$ & 73.75 & 2.95 & .83 & 65.5 & 2.62 & 1.24 & 1.00 & .32 & .32 \\
\hline Fear $200 \mathrm{~ms}$ & 28.75 & 1.15 & 1.14 & 50 & 2.0 & 1.45 & -2.08 & .04 & -.66 \\
\hline Fear $500 \mathrm{~ms}$ & 36.25 & 1.45 & 1.23 & 52.50 & 2.10 & 1.48 & -1.51 & .14 & -.48 \\
\hline Fear $1 \mathrm{~s}$ & 37.50 & 1.50 & 1.10 & 51.25 & 2.05 & 1.66 & -1.24 & .22 & -.40 \\
\hline Disgust $200 \mathrm{~ms}$ & 52.50 & 2.10 & 1.12 & 48.75 & 1.95 & 1.16 & .41 & .68 & .13 \\
\hline Disgust $500 \mathrm{~ms}$ & 75 & 3.00 & 1.12 & 65.50 & 2.62 & 1.40 & .96 & .34 & .30 \\
\hline Disgust $1 \mathrm{~s}$ & 77.50 & 3.10 & 1.07 & 70.25 & 2.81 & 1.33 & .77 & .45 & .24 \\
\hline Sadness $200 \mathrm{~ms}$ & 47.50 & 1.90 & 1.12 & 41.75 & 1.67 & 1.24 & .63 & .53 & .19 \\
\hline Sadness $500 \mathrm{~ms}$ & 55 & 2.20 & 1.54 & 39.25 & 1.57 & 1.33 & 1.40 & .17 & .44 \\
\hline Sadness $1 \mathrm{~s}$ & 52.50 & 2.10 & 1.37 & 40.50 & 1.62 & 1.40 & 1.11 & .27 & .34 \\
\hline Surprise $200 \mathrm{~ms}$ & 53.75 & 2.15 & 1.27 & 44 & 1.76 & 1.26 & .98 & .33 & .30 \\
\hline Surprise $500 \mathrm{~ms}$ & 53.75 & 2.15 & 1.27 & 40.50 & 1.62 & 1.20 & 1.38 & .18 & .43 \\
\hline \multirow[t]{2}{*}{ Surprise $1 \mathrm{~s}$} & 56.25 & 2.25 & 1.33 & 53.50 & 2.14 & 1.32 & .25 & .80 & .08 \\
\hline & $\begin{array}{c}\text { Accuracy } \\
(\%)\end{array}$ & Mean & $S D$ & $\begin{array}{c}\text { Accuracy } \\
(\%)\end{array}$ & Mean & $S D$ & $Z^{1}$ & $p$ & $d$ \\
\hline Happiness $200 \mathrm{~ms}$ & 97.50 & 3.90 & .447 & 94 & 3.76 & .539 & -1.29 & .20 & .29 \\
\hline Happiness $500 \mathrm{~ms}$ & 97.50 & 3.90 & .308 & 98.75 & 3.95 & .218 & -.64 & .53 & -.20 \\
\hline Happiness $1 \mathrm{~s}$ & 98.75 & 3.95 & .224 & 94 & 3.76 & .944 & -.48 & .63 & .32 \\
\hline
\end{tabular}

Note. ${ }^{1}$ The Kolmogorov-Smirnov test was used to verify the normal distribution of variables. Mann-Whitney $Z$ Test Value was used to assess group differences in happiness recognition due to the scores do not show normal distribution in the subsamples. PCL: YV = Psychopathy Checklist: Youth Version. $S D=$ standard deviation.

stimulus exposure time, making it possible to investigate relationships between stimulus duration and the ability to identify facial expressions of emotion.

Previous studies addressing facial affect recognition by antisocial individuals, including samples of youth and adults with psychopathic traits, have employed a variety of different stimulus durations. A significant proportion of these studies have presented stimuli for three seconds (Blair \& Cipolotti, 2000; Blair \& Coles, 2000; Blair, Colledge, Murray, \& Mitchell, 2001; Blair et al., 2004; Mitchell, Avny, \& Blair, 2006). Other studies utilized periods longer than three seconds (McCown, Johnson, \& Austin, 1986; Pham \& Philippot, 2010; Walz \& Benson, 1996). Some investigations presented stimuli for two seconds (Dadds et al., 2006; Stevens et al., 2001) or for one second (Kosson et al., 2002). A study by Eisenbarth, Alpers, Segrè, Calogero and Angrilli (2008) appears to be the only prior study presenting facial stimuli for less than one second (i.e., $33 \mathrm{~ms}$ ) in a sample of participants (in this case, adult women) with psychopathic features.

Recently, several authors have begun to examine whether the deficit may depend on the nature of the emotional stimuli presented. Hastings et al. (2008) presented facial affective stimuli at two different levels of intensity, $60 \%$ and $100 \%$. They found that psychopathy scores were associated with poorer recognition of facial affect at $60 \%$ but not at $100 \%$ intensity, suggesting the possibility that psychopathic individuals may have greater difficulty in processing more difficult or more subtle emotional cues. Thus, ample methodological diversity exists in terms of the stimulus presentation times in prior studies investigating the recognition of facial expressions of emotion in antisocial populations. However, very few prior studies have centered on adolescents. To our knowledge, no 
prior studies of adolescents utilized stimulus presentation periods shorter than one second, and no prior studies of psychopathy have manipulated facial stimulus durations. Consequently, the present study sought to investigate performance at three different stimulus presentation times within a sample of adolescents. The briefest stimulus duration of $200 \mathrm{~ms}$ was selected in part because recent evidence suggests that durations of approximately this duration are necessary to allow accurate identification of facial expressions (Schyns, Petro, \& Smith, 2009). In all the comparisons of adolescents with and without psychopathic traits, significant statistical differences in the two groups' performances appeared only for fear and only when faces were presented for only 200 milliseconds. At other stimulus durations, group differences were less robust when identifying this same emotion. However, the effect sizes also demonstrated a moderate difference between the groups for fear recognition at $500 \mathrm{~ms}$, raising the possibility that this difference would prove significant with larger samples. Interestingly, these two differences were the only group differences yielding moderate effect sizes, although there were small-to-moderate effect sizes observed for fear at 1 second, and for sadness and surprise at $500 \mathrm{~ms}$.

Among the basic emotions, Marsh and Blair (2008) have argued that deficits in identifying fear and sadness may be more directly connected to antisocial behavior. The identification of cues for these emotions may be important to the inhibition of inappropriate behaviors (Walker \& Laister, 1994). In terms of identifying fear, the amygdala, described by Ramachandran and Blakeslee (1998) as the entrance to the limbic system, performs an essential role (Adolphs, 2002). Neuroimaging findings have repeatedly corroborated the contribution of the amygdala in recognizing this emotion (Murphy, Nimmo-Smith, \& Lawrence, 2003). Moreover, scholars have postulated that amygdala dysfunction is one of the factors directly contributing to the development of psychopathy (Patrick, 1994), and neuroimaging studies of psychopathic offenders corroborate this view (Birbaumer et al., 2005; Kiehl et al., 2001).

The present study suggests that the implications of this dysfunction for the sphere of social cognition may be subtle in youth with psychopathic tendencies. Because the differences were significant only for the shortest stimulus presentation period examined, it is likely that individuals with psychopathic features will not misconstrue fearful expressions under all conditions. Rather, such youth may be especially prone to misinterpret others' emotional reactions when facial affect cues are quite brief. However, because social interactions are frequently characterized by the simultaneous presence of multiple cues that change from moment to moment, it is plausible that similar deficits in fear recognition may interfere with behavioral regulation under real-world conditions whenever multiple and complex cues are present.

Investigating the possible deficits of this population in recognizing basic facial emotions requires more advanced methodologies. Different studies have employed different methods for investigating the deficits of psychopaths in identifying facial expressions of basic emotions. Despite these differences, data consistent with more specific deficits in fear processing have been found for antisocial samples and, even more specifically, with samples of psychopathic individuals (Marsh \& Blair, 2008). Deficits in identifying sadness did not appear in the present study when comparing adolescents with psychopathic traits with the control group.

Considering 200 milliseconds as a sufficient duration for most individuals to recognize an emotion (Schyns et al., 2009), it can be hypothesized that, within this brief time period, an individual cannot re-examine all of the information that he or she perceives. However, when the same facial expressions were presented for 500 milliseconds, group differences in performance were not statistically significant. In this condition, the performance of adolescents with psychopathic traits came closer to that of the control group. As shown in Table 1, facial affect recognition performance of youth without psychopathic traits was quite stable across these two conditions. The same cannot be said for the group with psychopathic traits. These youth improved by over $25 \%$ as stimulus duration increased from 200 to $500 \mathrm{~ms} \mathrm{(vs.} \mathrm{5 \%} \mathrm{for} \mathrm{youth}$ without psychopathic traits). Although none of the other comparisons of the within-group differences shown by the two groups appear this dramatic, the table also shows that, even at a stimulus duration of 1 second the performance of youth with psychopathic features appears substantially poorer for fear recognition (1.50) than for any of the other emotions examined (next lowest mean $=2.10$ for sadness).

One possible explanation for these findings is based on evidence that decreasing stimulus presentation time may diminish the importance of top-down perceptual processes (Bargh \& Chartrand, 1999). Consequently, a shorter period may favor reliance on some automatic processes in both groups. However, for the group of adolescents with psychopathic traits, a reduced capacity for experiencing fear may contribute towards a weaker ability to infer fear based on automatic emotion processing mechanisms. Even if the obtained data are not conclusive, they do corroborate the perspective that individuals with psychopathic tendencies are not pervasively unable to perceive negative emotions. They may, however, experience some difficulty in identifying specific emotions under specific conditions, which should be investigated further. Even a difficulty in recognizing fear when it is briefly presented or presented in concert with other conflicting and complex information could interfere in the socialization process, contributing towards the development of psychopathy. Given this, other studies of adolescents are warranted, including studies that examine youth within specific age ranges in order to establish the robustness of these deficits in different developmental stages.

The limitations of the present study include sample size. Although the size of the current sample was compa- 
Vasconcellos, S. J. L., Salvador-Silva, R., Gauer, V. \& Gauer, G. J. C. (2014). Psychopathic Traits in Adolescents and Recognition of Emotion in Facial Expressions.

rable with that in many prior studies of psychopathy and emotional processing, the moderate effect size obtained for the group difference in fear recognition at $500 \mathrm{~ms}-$ and even some of the other small-to-moderate effect sizes obtained for other emotions - might prove reliable in a larger sample. Using other facial expression programs such as Ekman's Micro Expression Training Tool or Subtle Expressions Training Tool would also help in investigating the extent of these differences. The use of such tools would also contribute towards evaluating the true need for adapting the instruments used to measure facial affect recognition as a means of obtaining more precise data in different countries. Future studies could also employ additional stimulus presentation periods shorter than one second and of different durations than those used in this study. Comparing intragroup performances given different stimulus durations may illuminate the robustness of the association between stimulus duration and the ability to identify emotions in youth and adults with psychopathic tendencies. Moreover, the current study did not incorporate other social cues that could facilitate the identification of facial expressions given very brief stimulus presentation periods. Findings comparing performance with one sort of affective cue (e.g., facial expressions, vocalizations) to performance given two or three cues could improve our understanding of emotional processing in the real world and may shed light on the question of whether individuals with psychopathic traits are able to compensate for slight difficulties in identifying other people's emotions when multiple cues are present, or whether the presence of multiple cues only exacerbates the kinds of performance impairments observed in this study. Limitations such as these illustrate the need for additional studies in this field, including studies that replicate the methods used here and studies that further improve upon them.

\section{References}

Adolphs, R. (2002). Neural systems for recognition emotion. Current Opinion in Neurobiology, 12, 169-177. doi:10.1016/ S0959-4388(02)00301-X

Bargh, J. A., \& Chartland, T. L. (1999). The unbearable automaticity of being. American Psychologist, 54, 462-479. doi:10.1037/0003-066X.54.7.462

Birbaumer, N., Veit, R., Lotze, M., Erb, M., Hermann, C., Grodd, W., \& Flor, H. (2005) Deficient fear conditioning in psychopathy: A functional magnetic resonance imaging study. Archives of General Psychiatry, 62, 799-805. doi:10.1001/ archpsyc.62.7.799

Blair, R. J. R. (2008). The cognitive neuroscience of psychopathy and implications for judgments of responsibility. Neuroethics, 1, 149-157. doi:10.1007/s12152-008-9016-6

Blair, R. J. R., \& Cipolotti, L. (2000). Impaired social response reversal: A case of acquired sociopathy'. Brain, 123(6), 1122-1141.

Blair, R. J. R., \& Coles, M. (2000). Expression recognition and behavioural problems in early adolescence. Cognitive Development, 15(4), 421-434.
Blair, R. J. R., Colledge, E., Murray, L., \& Mitchell, D. G. (2001). A selective impairment in processing of sad and fearful expressions in children with psychopathic tendencies. Journal of Abnormal Child Psychology, 29, 491-498. doi:10.1023/A:1012225108281

Blair, R. J. R., Mitchel, D. G. V., Perchardt, K. S., Colledge, E., Leonard, R. A., Shine, J. H., ...Perrett, D. I. (2004). Reduced sensitivity to others' fearful expressions in psychopathic individuals. Personality and Individual Differences, 37, 11111112. doi:10.1016/j.paid.2003.10.008

Blair, R. J. R., Mitchel, D. G. V., Richell, R., Kelly, S., Leonard, A., Newman, C., \& Scott, S. (2002). Turning a deaf ear to fear: Impairment recognition in vocal affect in psychopathy individuals. Journal of Abnormal Psychology, 111, 682-686. doi:10.1037/0021-843X.111.4.682

Cleckley, H. (1976). The mask of sanity ( $5^{\text {th }}$ ed.). St. Louis, MO: Mosby.

Dadds, M. R., Perry, Y., Hawes, D. J., Merz, S. Riddell, A. C., Haines, D. J., ...A Abeygunawardane, A. I. (2006). Attention to the eyes and fear-recognition deficits in child psychopathy. British Journal of Psychiatry, 189, 280-281. doi:10.1192/bjp. bp. 105.018150

Del Gaizo, A. L., \& Falkenbach, D. M. (2007). Primary and secondary psychopathic-traits and their relationship to perception and experience of emotion. Personality and Individual Differences, 45, 206-212. doi:10.1016/j.paid.2008.03.019

Dolan, M., \& Fullam, R. (2006). Fear affect recognition deficits in personality-disordered offenders: Association with psychopathy. Psychological Medicine, 36, 1563-1569. doi:10.1017/ S0033291706008634

Eisenbarth, H., Alpers, G. W., Segrè, D., Calogero, A., \& Angrilli, A. (2008). Categorization and evaluation of emotional faces in psychopathic women. Psychiatry Research, 159, 189-195. doi:10.1016/j.psychres.2007.09.001

Ekman, P. (1992). Facial expression of emotion: New findings, new questions. Psychological Science, 3, 34-38. doi:10.1111/j.1467-9280.1992.tb00253.x

Ekman, P. (2003). Emotions revealed: Recognizing faces and feelings to improve communication and emotional life. New York: Times Book.

Forth, A. E., Kosson, D. S., \& Hare, R. D. (2003). Hare psychopathy youth version manual. Toronto, Canada: MultiHealth Systems.

Glass, S. J., \& Newman, J. P. (2006). Recognition of facial affect in psychopathic offenders. Journal of Abnormal Psychology, 115, 815-820. doi:10.1037/0021-843X.115.4.815

Hansen, A. L., Johnesen, B. H., Waage, L., \& Thayer, J. F. (2008). Brief communication: Psychopathy and recognition of facial expression of emotion. Journal of Personality Disorders, 22, 639-645. doi:10.1521/pedi.2008.22.6.639

Hare, R. D. (1993). Without conscience: The disturbing world of psychopaths among us. New York: Pocket Books.

Hare, R. D. (2003). The Hare Psychopathy Checklist-Revised ( $2^{\text {nd }}$ ed.). Toronto, Canada: Multi Health Systems.

Hastings, M. E., Tangney, J. P., \& Stuewig, J. (2008). Psychopathy and identification of facial expressions of emotion. Personality and Individual Differences, 44, 1474-1483. doi:10.1016/j.paid.2008.01.004

Kiehl, K. A., Smith, A. M., Hare, R. D., Mendrek, A., Forster, B. B., Brink, J., \& Liddle, P. F. (2001). Limbic abnormalities in affective processing by criminal psychopaths as revealed by functional magnetic resonance imaging. Biological Psychiatry, 50, 677-684. doi:10.1016/S0006-3223(01)01222-7 
Kosson, D. S., Suchy, Y., Mayer, A. R., \& Libby, J. (2002). Facial affect recognition in criminal psychopaths. Emotion, 2, 398-411. doi:10.1037/1528-3542.2.4.398

Marsh, A. A., \& Blair, R. J. R. (2008). Deficits in facial affect recognition among antisocial populations: A meta-analysis. Neuroscience and Biobehavioral Reviews, 32, 454-465. doi:10.1016/j.neubiorev.2007.08.003

McCown, W., Johnson, J., \& Austin, S. (1986). Inability of delinquents to recognize facial affects. Journal of Social Behavior and Personality, 1, 489-496.

Mitchell, D. G., Any, S. B., \& Blair, R. J. (2006). Divergent patterns of aggressive and neurocognitive characteristics in acquired versus developmental psychopathy. Neurocase, 12, 164-178. doi:10.1080/13554790600611288

Murphy, F. C., Nimmo-Smith, I., \& Lawrence, A. D. (2003). Functional neuroanatomy of emotions: A meta-analysis. Cognitive Affective and Behavioral Neuroscience, 3, 207-233. doi:10.3758/CABN.3.3.207

Patrick, C. J. (1994). Emotion and psychopathy: Startling new insights. Psychophysiology, 31(4), 319-330.

Pham, T. H., \& Philippot, P. (2010). Decoding of facial expression of emotion in criminal psychopaths. Journal of Personality Disorders, 24, 445-459. doi:10.1521/pedi.2010.24.4.445

Ramachandran, V. S., \& Blakeslee, S. (1998). Phantoms in the brain: Probing the mysteries of the human mind. New York: William Morrow.

Ronchetti, R., Davoglio, T. R., Salvador-Silva, R., Vasconcellos, S. J. L., \& Gauer, G. J. C. (2010). Inventário de Psicopatia Hare: Versão Jovens (PCL:YV): Estudo preliminar em amostra adolescente brasileira. Interamerican Journal of Psychology, 44, 411-417. Recuperado em http://www.redalyc.org/ articulo.oa? $\mathrm{id}=28420658017$

Schyns, P. G., Petro, L. S., \& Smith, M. L. (2009). Transmission of facial expressions of emotion co-evolved with their efficient decoding in the brain: Behavioral and brain evidence. Plos one, 4(5), 5625. doi:10.1371/journal.pone.0005625

Stevens, D., Charman, T., \& Blair, R. J. (2001). Recognition of emotion in facial expressions and vocal tones in children with psychopathic tendencies. Journal of Genetic Psychology, 162, 201-211. doi:10.1080/00221320109597961

Walker, D. W., \& Leister, C. (1994). Recognition of facial affect cues by adolescent with emotional and behavioral disorders. Behavioral Disorders, 19, 269-276.

Walz, N. C., \& Benson, B. A. (1996). Labeling and discrimination of facial expressions by aggressive and nonaggressive men with mental retardation. American Journal of Mental Retardation, 101, 282-291. 